\title{
Tyrosine-Protein Kinase TEC
}

National Cancer Institute

\section{Source}

National Cancer Institute. Tyrosine-Protein Kinase TEC. NCI Thesaurus. Code C30083.

Tyrosine-protein kinase Tec (631 aa, 74 kDa) is encoded by the human TEC gene. This protein plays a role in protein phosphorylation and signal transduction. 